\title{
Anurans in a Subarctic Tundra Landscape Near Cape Churchill, Manitoba
}

\author{
Matthew E. Reiter ${ }^{1,2,3}$, Clint W. Boal ${ }^{4}$, and David E. Andersen ${ }^{5}$ \\ ${ }^{1}$ Minnesota Cooperative Fish and Wildlife Research Unit, Department of Fisheries, Wildlife, and Conservation Biology, \\ University of Minnesota, 200 Hodson Hall, 1980 Folwell Avenue, Saint Paul, Minnesota, 55108 USA \\ ${ }^{2}$ Corresponding author; email: mreiter@prbo.org \\ ${ }^{3}$ Current address: PRBO Conservation Science, 3820 Cypress Drive \#11, Petaloma, California 94954 USA \\ ${ }^{4}$ U.S. Geological Survey, Texas Cooperative Fish and Wildlife Research Unit, Texas Tech University, Lubbock, Texas 79409 \\ USA \\ ${ }^{5}$ U.S. Geological Survey, Minnesota Cooperative Fish and Wildlife Research Unit, University of Minnesota, 200 Hodson Hall, \\ 1980 Folwell Avenue, Saint Paul, Minnesota 55108 USA
}

Reiter, Matthew E., Clint W. Boal, and David E. Andersen. 2008. Anurans in a subarctic tundra landscape near Cape Churchill, Manitoba. Canadian Field-Naturalist 122(2): 129-137.

Distribution, abundance, and habitat relationships of anurans inhabiting subarctic regions are poorly understood, and anuran monitoring protocols developed for temperate regions may not be applicable across large roadless areas of northern landscapes. In addition, arctic and subarctic regions of North America are predicted to experience changes in climate and, in some areas, are experiencing habitat alteration due to high rates of herbivory by breeding and migrating waterfowl. To better understand subarctic anuran abundance, distribution, and habitat associations, we conducted anuran calling surveys in the Cape Churchill region of Wapusk National Park, Manitoba, Canada, in 2004 and 2005. We conducted surveys along 1-km transects distributed across three landscape types (coastal tundra, interior sedge meadow-tundra, and boreal forest-tundra interface) to estimate densities and probabilities of detection of Boreal Chorus Frogs (Pseudacris maculata) and Wood Frogs (Lithobates sylvaticus). We detected a Wood Frog or Boreal Chorus Frog on $22(87 \%)$ of 26 transects surveyed, but probability of detection varied between years and species and among landscape types. Estimated densities of both species increased from the coastal zone inland toward the boreal forest edge. Our results suggest anurans occur across all three landscape types in our study area, but that species-specific spatial patterns exist in their abundances. Considerations for both spatial and temporal variation in abundance and detection probability need to be incorporated into surveys and monitoring programs for subarctic anurans.

Key Words: Boreal Chorus Frog, Pseudacris maculata, Wood Frog, Lithobates sylvaticus, subarctic tundra, Manitoba.

Declining amphibian populations have received increased attention in North America (Bury et al. 1995) and elsewhere (Alford and Richards 1999; Burrowes et al. 2004; Stuart et al. 2004; Lips et al. 2005). Factors implicated in the decline of North American amphibians inhabiting temperate regions include habitat fragmentation and loss (Johnson 1992), pollution (Bishop 1992), and global climate change (Herman and Scott 1992; Ovaska 1997; Pounds 2001). Changes in global temperatures and increased intensity of UV-B radiation predicted in climate change models (Kickert et al. 1999) could influence the distribution and abundance of anurans throughout North America (Mandronich 1993; Ovaska 1997; Pounds 2001). Arctic and subarctic regions of North America are predicted to experience dramatic changes in climate (Madronich 1993). Anurans in these northern regions are at the edges of their distribution and environmental tolerances, and will likely be affected by changes in climate (Ovaska 1997). For example, increasing average temperatures may result in expansion of some anuran species into regions formerly too cold to support them (Ovaska 1997), but increasing UV-B radiation could have a significant negative effect on the growth and survival of some anurans (Crump et al. 1999).
Changes in some arctic and subarctic landscapes due to high rates of herbivory by breeding and migrating waterfowl (Ankney 1996), especially Lesser Snow Geese (Chen caerulescens caerulescens; Kerbes et al. 1990; Jano et al. 1998) might also influence anurans in these landscapes. Herbivory rates have increased substantially along with the exponential increase of Lesser Snow Goose populations, which are thought largely to result from anthropogenic influences on their wintering grounds (Ankney 1996). Extensive feeding on below ground biomass by Snow Geese in tundra meadows and wetlands may reduce the abundance of small wetlands (Abraham and Jefferies 1997) and change the chemistry of the remaining aquatic habitats, influencing their suitability to support anuran reproduction (Jefferies 2000). Recent data, from near Cape Churchill in Manitoba, suggested anuran abundance was lower in tundra wetlands with higher impacts on vegetation from goose herbivory when compared to areas with less impacted vegetation (Mannan 2008). Overall, however, the status of anurans inhabiting subarctic regions remains poorly understood. Because of this, the effects of habitat loss or alteration, and global climate change on anurans in arctic and subarctic regions cannot be assessed. 
Declines in amphibian populations have resulted in recent efforts to establish standardized monitoring programs for amphibians in North America (e.g., North American Amphibian Monitoring Program; Bishop and Petit 1992; Heyer et al. 1994; Weir and Mossman 2004) although these monitoring efforts have not been extended to subarctic regions. Anurans have been reported to occur in the vicinity of Churchill, Manitoba (Shelford and Twomey 1941; Wrigley 1974), but there are no data available concerning anurans on the Hudson Bay Lowlands within Wapusk National Park in Manitoba, Canada. During a pilot study in June 2002, we detected both Wood Frogs (Lithobates sylvaticus) and Boreal Chorus Frogs (Pseudacris maculata) on standardized surveys in Wapusk National Park. Based on these preliminary surveys (C. W. Boal and D. E. Andersen, unpublished data), we initiated a project in 2004 to assess anuran density, distribution, and habitat associations in the tundra and boreal forest-tundra ecotone of Wapusk National Park. Specifically, we collected data to (1) describe anuran species composition in the region and (2) compare the probability of detection and density of anurans across years, species, and three landscape types.

\section{Study Area}

The Hudson Bay Lowlands in Manitoba are an area of low-lying tundra and northern boreal forest ecosystems along the western shores of Hudson Bay (Figure 1). They extend from southern James Bay in Ontario $\left(52^{\circ} 54^{\prime} \mathrm{N}, 82^{\circ} 10^{\prime} \mathrm{W}\right)$ northwest to just north of the town of Churchill, Manitoba $\left(59^{\circ} 27^{\prime} \mathrm{N}, 94^{\circ} 53^{\prime} \mathrm{W}\right)$. South of Cape Churchill and within Wapusk National Park $\left(11475 \mathrm{~km}^{2}\right)$ lies a narrow strip of coastal tundra habitat where coastal salt marshes, beach ridges, and freshwater sedge meadows compose the major habitat types (Didiuk and Rusch 1979; Brook 2001). In this region, the northern boreal forest begins $\sim 10 \mathrm{~km}$ from the Hudson Bay coastline. The climate is influenced strongly by Hudson Bay, which can remain frozen for up to 9 months of the year. Average daily temperatures ranged from $-26.7^{\circ} \mathrm{C}$ in January to $12^{\circ} \mathrm{C}$ in July. Average monthly precipitation ranged from $15.7 \mathrm{~mm}$ in February to $68.3 \mathrm{~mm}$ in August (Environment Canada, www.climate.weatheroffice.ec.gc.ca).

\section{Methods}

\section{Landscape classification}

We used ArcView ${ }^{\circledR} 3.3$ (Environmental Systems Research Institute, Inc. (C) 1992 - 2002; use of trade names does not imply endorsement by the U.S. Geological Survey, the University of Minnesota, or Texas Tech University), the vegetation classification layer developed by Brook (2001), and habitat categorizations by Didiuk and Rusch (1979) to delineate that portion of Wapusk National Park north of the Broad River and east of the western edge of La Pérouse Bay into three landscape types based on physiography and vegetation: (1) Coastal beach ridge - sedge meadow (BRSM), (2) Interior sedge meadow (ISM), and (3) Boreal forest - tundra interface (TRAN; Figure 1). The BRSM stratum $\left(\sim 330 \mathrm{~km}^{2}\right)$ extended from the high tide line to approximately $3-5 \mathrm{~km}$ inland. This stratum was characterized by low relief, continuous permafrost, poor drainage, beach ridges, coastal marshes, and coastal tundra vegetation (Wellein and Lumsden 1964; Didiuk and Rusch 1979). The ISM stratum $\left(\sim 394 \mathrm{~km}^{2}\right)$ began at the western edge of the BRSM stratum and extended westward toward the northern boreal forest edge. This stratum was characterized by reduced numbers of beach ridges, extensive sedge and grass meadow complexes, and shallow water bodies. The TRAN stratum $\left(\sim 397 \mathrm{~km}^{2}\right)$ began where spruce (Picea spp.) trees became increasingly present and consisted primarily of lichen spruce bog, sphagnum spruce bog, lichen melt pond bog, and sedge meadow vegetation types (Brook 2001). Combined, these strata extended from Cape Churchill $\left(58^{\circ} 50^{\prime} \mathrm{N}\right)$ south to the mouth of the Broad River $\left(58^{\circ} 10^{\prime} \mathrm{N}\right)$ and from the Hudson Bay coastline $\left(93^{\circ} 05^{\prime} \mathrm{W}\right)$ west to La Pérouse Bay $\left(95^{\circ} 30^{\prime} \mathrm{W}\right)$.

\section{Transect surveys}

In 2004 and 2005, we used ArcView ${ }^{\circledR} 3.3$ to randomly establish coordinates for the origin of $1-\mathrm{km}$ transects in each stratum. To maximize sample size (i.e., number of transects surveyed) in 2005, we randomly located coordinates $\geq 3 \mathrm{~km}$ from any of the 2004 transects. We were transported by helicopter to each starting location. At the origin, we generated a random compass bearing along which to traverse the transect. When a random bearing would send the survey crew through impassable terrain (e.g., lakes, rivers) we randomly selected an alternative bearing. We waited 5 minutes after the helicopter departed, landed near the end of the transect, and shut down before beginning a survey to reduce bias from helicopter disturbance.

Because we had few anuran detections on preliminary surveys conducted at points along transects surveyed in 2002 (C. W. Boal and D. E. Andersen, unpublished data), we used unbounded transects to survey anurans in 2004 and 2005, and recorded all aural and visual detections of anurans along transects. The primary observer walked each transect and recorded a track of the survey route using a handheld Global Positioning System (GPS) unit. At each anuran detection, the observer recorded the species detected, Call Index Value [CIV: 1 = individuals counted, no overlap between calls; 2 = individuals counted but calls overlap; $3=$ full chorus, calls are constant and overlapping (Weir and Mossman 2004)] by species, estimated distance and bearing from transect line to calling anurans (estimated with a laser rangefinder and a compass), general landscape and vegetation characteristics, weather conditions, and time of day of the observation. We recorded multiple detections from the same location off the transect as a single detection so as to 


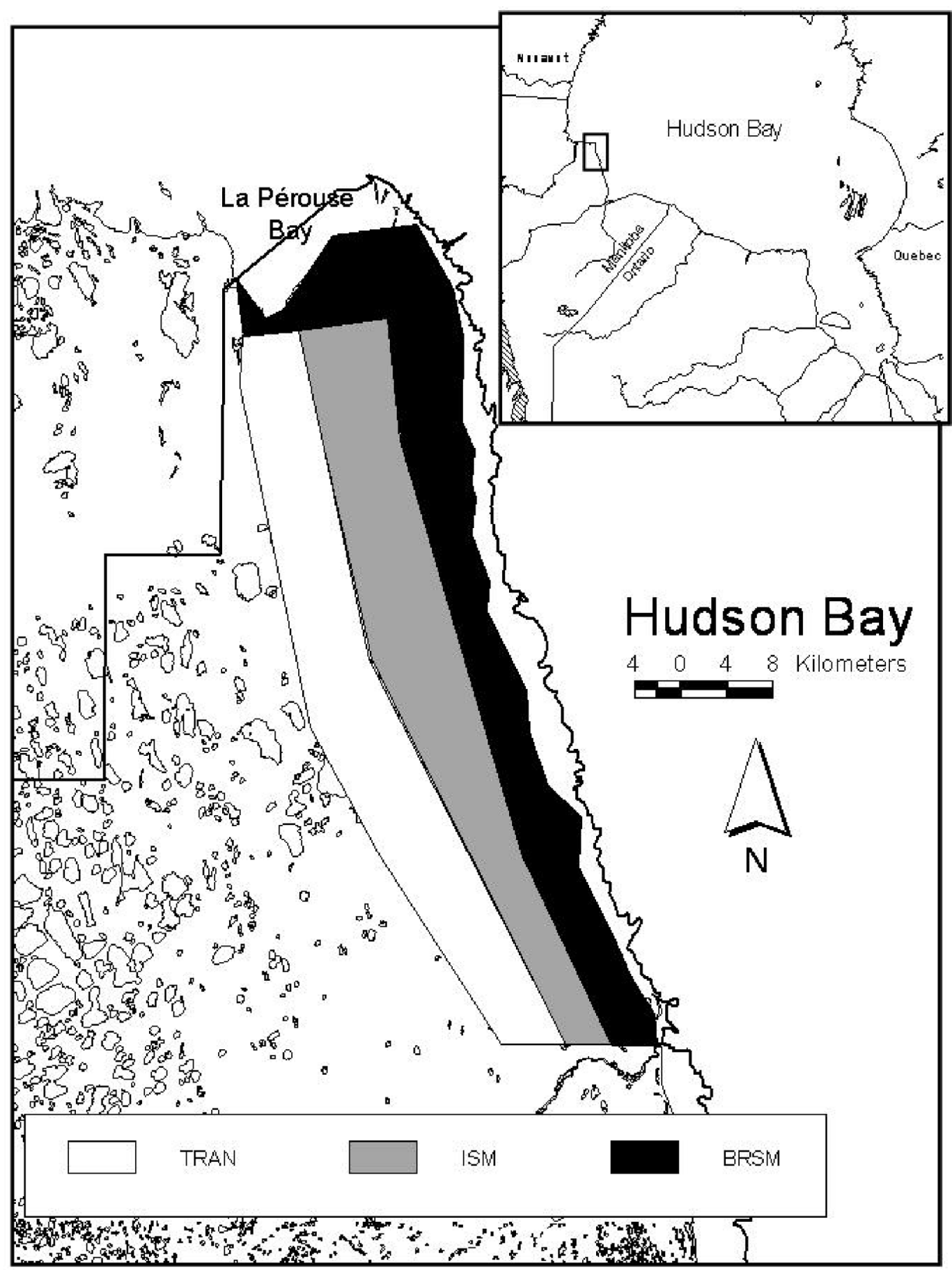

FIGURE 1. Three vegetation/physiographic strata at Cape Churchill: beach ridge-sedge meadow (BRSM), interior sedge meadow (ISM) and boreal forest-tundra interface (TRAN) within Wapusk National Park, Manitoba. 
not double count anurans. We followed North American Amphibian Monitoring Program (NAAMP) weather protocols (www.pwrc.usgs.gov/NAAMP/protocol) and did not survey in rain or in winds $>$ Beaufort 4 $(\sim 25-30 \mathrm{~km}$ per $\mathrm{hr})$. In addition, because anurans in these landscapes call during daylight hours in June at this latitude (Manann 2008), there are not periods of complete darkness, and because Polar Bears (Ursus maritimus) are a safety concern, especially during twilight periods when they are harder to detect, we conducted surveys during daylight hours.

\section{Data analysis}

We used program DISTANCE (Thomas et al. 2005) to analyze transect data from 2004 and 2005 and fit detection function models. We ranked models using Akaike's Information Criterion corrected for small sample size ( $\mathrm{AIC}_{\mathrm{c}}$; Burnham and Anderson 2002). Because of the low number of detections for some species in some strata, we pooled data to increase sample size and precision of density estimates derived from DISTANCE. We followed methods described in Buckland et al. (2001) to assess the validity of pooling across years, species, and strata. We assessed frequency of detection as a function of distance from the transect to determine whether anurans on the transect line were detected with probability equal to 1 (an assumption of distance sampling). Our qualitative analyses indicated that anurans close to the transect line were detected at lower frequency than those away from the line. We corrected for this possible observer effect on the probability of detection by removing all detections at $<10 \mathrm{~m}$ from the transect during analysis in DISTANCE, and assuming the probability of detection at $10 \mathrm{~m}$ was one. Anuran detections of CIV 2 or CIV 3 indicated that $>1$ frog was present and we incorporated cluster size (i.e., how many animals were present) in DISTANCE. We used the CIV score of each detection as a relative measure of the number of anurans present (e.g., CIV of 2 indicated 2 anurans present). This approach resulted in minimum density estimates.

We fitted four separate general detection functions (uniform, half-normal, negative-exponential, hazard rate; Buckland et al. 2001) to model the observed decline in anuran detections as a function of distance from the transect in the analysis of each of the following scenarios: (1) Anuran detections were pooled across species and strata to compare between years (hereafter, YEAR); (2) Detections of each species were pooled across years and strata to compare between Wood Frogs and Boreal Chorus Frogs (hereafter, SPECIES); (3) Anuran detections were pooled across species and years to compare among strata (hereafter, STRATA). Due to the low number of detections in some scenarios, we allowed only one cosine adjustment term in detection function models. We used the model best supported by the data (e.g., lowest $\mathrm{AIC}_{\mathrm{c}}$ ) to estimate the probability of detection $(\hat{p})$ and anu- ran density $(\hat{D})$ for each year, species, and stratum. Because we were also interested in variation within species across strata, but the number of detections was too small to estimate a detection function with reasonable precision, we calculated the encounter rate ( $E R=$ the number of detections per $\mathrm{km}$ surveyed) for each species within each stratum. We pooled data across years to calculate encounter rates and evaluated variation in encounter rates between species within strata, and among strata within species, by comparing 95\% CI (Buckland et al. 2001).

\section{Results}

Transect summary

We surveyed 15 transects (five in each stratum) in 2004 and 11 transects (three in the BRSM stratum and four in both the ISM and TRAN strata) in 2005. We conducted surveys from 29 June to 2 July 2004 between 0930 and 1900 CDT and from 14 to 19 June 2005 between 0922 and 1526 CDT. We surveyed a total of $24.6 \mathrm{~km}$, with transects $(n=26)$ averaging $946 \mathrm{~m}(\mathrm{SE}=18)$ in length. Five transects were $<900 \mathrm{~m}$ in length due to helicopter noise interference (e.g. the pilot started the helicopter prior to completion of a survey) or when the presence of a lake prevented surveying to the end of a transect. Surveys averaged 55 minutes to complete in 2004 and 64 minutes in 2005.

\section{Anuran detections \\ Year}

In 2004 , we detected $\geq 1$ frog on $11(73 \%)$ of 15 transects and in all three strata. We detected anurans aurally on 77 occasions. In 2005, we detected anurans on all 11 transects and in all three strata. We detected anurans aurally on 75 occasions and visually on two occasions (both were Wood Frogs). We used 64 detections in 2004 and 66 detections in 2005 for analysis with DISTANCE. Two detection function models received substantial support $\left(\Delta \mathrm{AIC}_{\mathrm{c}}<2.0\right)$ in 2004 , and four models received substantial support in 2005. Employing the models with the lowest $\mathrm{AIC}_{\mathrm{c}}$ for each year (Table 1), the estimated probability of detection was higher in $2005(\hat{p}=0.32)$ than in $2004(\hat{p}=0.13)$, based on a comparison of $95 \%$ CI. Although $95 \%$ CI overlapped, density estimates were over 2 times higher in 2004 than in 2005 (Table 2).

\section{Species}

Overall, we detected a Wood Frog, Boreal Chorus Frog, or both species on 22 (87\%) of 26 transects surveyed. We used 65 detections for analysis of both Wood Frogs and Boreal Chorus Frogs in DISTANCE. Based on $\triangle \mathrm{AIC}_{\mathrm{c}}$, one detection function model received substantial support for Wood Frogs, and three models were supported for Boreal Chorus Frogs (Table 1). The bestsupported models of detection resulted in estimates of probability of detection only slightly higher for Boreal Chorus Frogs $(\hat{p}=0.17)$ than for Wood Frogs $(\hat{p}=0.14$; Table 2$)$. The estimated density of Wood 
TABLE 1. Summary of detection function model selection for YEAR, SPECIES, and STRATA using program DISTANCE for Wood Frogs and Boreal Chorus Frogs at Cape Churchill, Manitoba. Models were ranked using Akaike's Information Criterion $\left(\mathrm{AIC}_{\mathrm{c}}\right.$ ) corrected for small sample sizes, and evaluated with $\Delta \mathrm{AIC}_{\mathrm{c}}\left(\mathrm{AIC}_{\mathrm{c}}-\right.$ minimum $\left.\mathrm{AIC}_{\mathrm{c}}\right)$ and Akaike weights $\left(w_{i}\right) . k$ was the number of estimable parameters in the model.

\begin{tabular}{|c|c|c|c|c|c|c|}
\hline & & Model & $\mathrm{AIC}_{\mathrm{c}}$ & $\Delta \mathrm{AIC}_{\mathrm{c}}$ & $w_{i}$ & $k$ \\
\hline \multirow[t]{6}{*}{ YEAR } & 2004 & Hazard rate & 278.32 & 0.00 & 0.54 & 2 \\
\hline & & Hazard rate $\mathrm{w} /$ cosine & 279.14 & 0.82 & 0.36 & 3 \\
\hline & 2005 & Half-normal & 349.94 & 0.00 & 0.31 & 1 \\
\hline & & Negative exponential w/ cosine & 349.97 & 0.43 & 0.25 & 2 \\
\hline & & Hazard rate $w /$ cosine & 350.15 & 0.61 & 0.23 & 3 \\
\hline & & Half-normal w/ cosine & 351.57 & 1.96 & 0.12 & 2 \\
\hline \multicolumn{7}{|l|}{ SPECIES } \\
\hline & Wood Frog & & & & & \\
\hline & & Hazard rate & 300.90 & 0.00 & 0.55 & 2 \\
\hline & Boreal Chorus Frog & & & & & \\
\hline & & Negative exponential & 338.55 & 0.00 & 0.44 & 1 \\
\hline & & Negative exponential w/ cosine & 340.44 & 1.89 & 0.17 & 2 \\
\hline & & Half-normal & 340.48 & 1.93 & 0.17 & 1 \\
\hline \multirow[t]{12}{*}{ STRATA } & BRSM & & & & & \\
\hline & & Negative exponential & 132.30 & 0.00 & 0.29 & 1 \\
\hline & & Uniform w/ cosine & 132.84 & 0.54 & 0.22 & 1 \\
\hline & & Half-normal & 132.87 & 0.57 & 0.22 & 1 \\
\hline & & Negative exponential w/ cosine & 134.01 & 1.71 & 0.12 & 2 \\
\hline & ISM & & & & & \\
\hline & & Half-normal & 172.71 & 0.00 & 0.32 & 1 \\
\hline & & Negative exponential w/ cosine & 172.97 & 0.26 & 0.28 & 2 \\
\hline & & Negative exponential & 174.59 & 1.88 & 0.12 & 1 \\
\hline & TRAN & & & & & \\
\hline & & $\begin{array}{l}\text { Negative exponential } \\
\text { Hazard rate }\end{array}$ & 321.05 & 0.00 & 0.39 & 1 \\
\hline & & & 321.51 & 0.46 & 0.31 & 2 \\
\hline
\end{tabular}

TABLE 2. Probability of anuran detection $(\stackrel{\wedge}{)})$ and estimated density $\left(\hat{\mathrm{D}}=\right.$ anurans per $\left.\mathrm{km}^{2}\right)$ of anurans at Cape Churchill, Manitoba derived from program DISTANCE when anuran detections were (1) pooled across species and strata, within each year (YEAR), (2) pooled across years and strata, within each species (SPECIES), and (3) pooled across years and species, within each stratum (STRATA). Models listed are detection functions that best fit the observed data given the models assessed based on Akaike's Information Criterion $\left(\mathrm{AIC}_{\mathrm{c}}\right)$.

\begin{tabular}{|c|c|c|c|c|c|c|}
\hline & & Model & $\stackrel{\hat{P}}{ }$ & $95 \% \mathrm{CI}$ & $\hat{D}$ & $95 \% \mathrm{CI}$ \\
\hline \multirow[t]{2}{*}{ YEAR } & 2004 & Hazard rate & 0.13 & $0.08,0.20$ & 102.25 & $51.61,202.55$ \\
\hline & 2005 & Half-normal & 0.32 & $0.26,0.39$ & 49.87 & $34.86,71.36$ \\
\hline \multirow[t]{2}{*}{ SPECIES } & Wood Frog & Hazard rate & 0.14 & $0.09,0.23$ & 56.76 & $29.78,108.20$ \\
\hline & Boreal Chorus Frog & Negative exponential & 0.17 & $0.12,0.23$ & 38.90 & $23.33,64.97$ \\
\hline \multirow[t]{3}{*}{ STRATA } & BRSM & Negative exponential & 0.32 & $0.17,0.59$ & 18.46 & $7.40,46.06$ \\
\hline & ISM & Half-normal & 0.30 & $0.22,0.40$ & 34.34 & $18.56,63.55$ \\
\hline & TRAN & Negative exponential & 0.09 & $0.07,0.12$ & 354.66 & $236.32,532.78$ \\
\hline
\end{tabular}

Frogs $\left(\hat{D}=56.8\right.$ per $\left.\mathrm{km}^{2}\right)$ was higher than for Boreal Chorus Frogs $\left(\hat{D}=38.9\right.$ per $\left.\mathrm{km}^{2}\right)$, although $95 \% \mathrm{CI}$ overlapped (Table 2).

\section{Strata}

During 2004 and 2005 surveys, we detected anurans on five $(63 \%)$ of eight transects in the BRSM stratum. We detected Wood Frogs on three $(38 \%)$ and Boreal Chorus Frogs on five (63\%) of the eight BRSM transects. The estimated encounter rate for Wood Frogs ( 0.38 detections per $\mathrm{km}$ ) was lower than for Boreal Chorus Frogs (2.41 detections per km), although there was a slight overlap of $95 \%$ CI (Table 3). CIVs varied by species and year (Figure 2A). In both 2004 and 2005, we detected more Boreal Chorus Frogs than Wood Frogs; however, overall total detections of both species were few along BRSM transects.

We detected anurans on eight $(89 \%)$ of nine transects surveyed in 2004 and 2005 in the ISM stratum. We detected both Wood Frogs and Boreal Chorus Frogs $\geq 1$ time on six $(67 \%)$ of nine transects. Estimated encounter rates for Wood Frogs and Boreal Chorus Frogs were 2.64 and 1.15 detections per km, respectively (Table 3). CIV 1 and CIV 2 were most common 
TABLE 3. Encounter rates (ER) for Wood Frogs and Boreal Chorus Frogs within each of three general landscape stratum at Cape Churchill, Manitoba, calculated as the number of detections $(n)$ divided by the distance traversed $(L)$.

\begin{tabular}{llcccc}
\hline \hline Species & Stratum & $n$ & $L(\mathrm{~km})$ & $E R(n / L)$ & $95 \%$ CI \\
\hline Wood Frog & BRSM & 3 & 7.88 & 0.38 & $0.09,1.69$ \\
& ISM & 23 & 8.73 & 2.63 & $1.14,6.09$ \\
Boreal Chorus Frog & TRAN & 39 & 8.40 & 4.64 & $2.83,7.62$ \\
& BRSM & 19 & 7.88 & 2.41 & $1.05,5.54$ \\
& ISM & 10 & 8.73 & 1.15 & $0.34,3.82$ \\
& TRAN & 36 & 8.40 & 4.29 & $2.65,6.92$ \\
\hline \hline
\end{tabular}

for both Wood Frogs and Boreal Chorus Frogs, and we detected few $(n=1)$ full choruses (CIV = 3; Figure 2B).

We detected anurans on all nine transects surveyed in the TRAN stratum in 2004 and 2005. We detected Wood Frogs and Boreal Chorus Frogs $\geq 1$ time on all transects we surveyed. Encounter rates for Wood Frogs and Boreal Chorus Frogs were 4.64 and 4.29 detections per $\mathrm{km}$, respectively (Table 3 ). We recorded a steady chorus $(\mathrm{CIV}=3)$ of Wood Frogs on all or part of three of five transects in 2004, but in 2005, all Wood Frog detections $(n=16)$ were discernable individuals $(\mathrm{CIV}=1$; Figure 2C). We detected Boreal Chorus Frogs 14 times in the TRAN stratum in 2004 and 25 times in 2005. The only time we detected a full chorus of Boreal Chorus Frogs was in the TRAN stratum in 2004.

Overall, we encountered Wood Frogs more often in the TRAN stratum than in the BRSM stratum, but there were no differences between encounter rates in ISM and TRAN or BRSM and ISM strata based on 95\% CI (Table 3). We also encountered Boreal Chorus Frogs most frequently in the TRAN stratum, but there were no significant differences in encounter rates among strata (Table 3 ). After pooling across species and years, we used 22, 33, and 75 detections in DISTANCE to model the detection function for BRSM, ISM, and TRAN strata, respectively. Four models received substantial support in the BRSM stratum, three models in the ISM stratum, and two models in the TRAN stratum (Table 1). Based on the model with the lowest $\mathrm{AIC}_{\mathrm{c}}$ for each stratum, the probability of detection was highest in the BRSM $(\hat{p}=0.32)$ stratum and declined heading inland to the ISM $(\hat{p}=0.30)$ and then TRAN $(\hat{p}=0.09)$ strata. The $95 \%$ CI for the estimated probability of detection overlapped between ISM and BRSM; however, the probability of detection in the TRAN zone was substantially lower, and its $95 \% \mathrm{CI}$ did not overlap with that of either the BRSM or ISM strata (Table 2). Estimates of anuran density were highest in the TRAN stratum $\left(\hat{D}=354.66\right.$ per $\left.\mathrm{km}^{2}\right)$, then progressively, and substantially, decreased the farther the survey was from the TRAN stratum, with $\hat{D}=34.34$ per $\mathrm{km}^{2}$ in ISM and $\hat{D}=18.46$ per $\mathrm{km}^{2}$ in BRSM (Table 2). Similar to the species-specific encounter rates, pooled species density estimates across strata also decreased from the TRAN to the ISM to the BRSM stratum.

\section{Discussion}

Despite extensive annual surveys for frogs and amphibians throughout much of North America (Weir and Mossman 2004), little is known about anuran species composition, landscape distribution, and general habitat associations in subarctic regions. We found Wood Frogs and Boreal Chorus Frogs in all three landscape types that we sampled in the subarctic region near Cape Churchill, Manitoba. Although our estimates suggested that the probability of detecting an anuran differed between 2004 and 2005, there was not a significant difference in estimated anuran densities across the study area between those two years. Probability of detection can be influenced by weather conditions such as wind, barometric pressure, and temperature (Oseen and Wassersug 2002). We are aware of no data describing the influence of weather variables on the detection of anurans in tundra habitats; however, recently initiated studies near Cape Churchill are designed to evaluate the effect of these factors on detection rates (D. E. Andersen, unpublished data). In this study, we conducted surveys in weather conditions deemed suitable for conducting surveys in more temperate regions of North America (Weir and Mossman 2004) to minimize the influence of weather on our results.

Seasonal and diurnal patterns in anuran calling behavior (Oseen and Wassersug 2002) can also influence detection probability of anurans, although calling patterns of anurans in subarctic and arctic landscapes, where daylight can extend for $\geq 20 \mathrm{hrs}$ in summer, are not well documented. Manaan (2008) reported anuran calling throughout the day and peak calling in the afternoon by both Boreal Chorus Frogs and Wood Frogs during June in a coastal tundra landscape near Cape Churchill. Although we conducted our surveys throughout the day in both years, we conducted some surveys later in the day in 2004 than in 2005. This may have influenced detection probabilities. In both years, our surveys occurred approximately 2 weeks prior to the median hatch date of Canada Geese (Branta canadensis) in the region, which is tied very closely to annual spring phenology and is variable among years (Walter 1999). Factors that influence Canada Goose 
nest initiation, such as snow melt, also likely affect the timing of reproduction of anurans.

Wood Frogs and Boreal Chorus Frogs were the only anurans we detected during our surveys, and the probability of detection and estimates of density were nearly the same for both species. Peak calling in the majority of anuran species is associated with the initiation of the breeding season (Wells 1977), so detection of anuran species is likely influenced by reproductive ecology. Wood Frogs in temperate regions are spring breeders (Oseen and Wassersug 2002) and Boreal Chorus Frogs also typically call early in the season (Corn and Muths 2002). The similarity in the breeding season of these species may have contributed to the similar estimates of probability of detection. However, temporal variation in calling behavior of these species in subarctic regions is unknown and inferences drawn from our estimates of density are limited by our study design, which incorporated logistical constraints imposed by working in a remote, subarctic landscape.

We did not detect anurans uniformly across our study area, nor were they distributed uniformly, with both Wood Frogs and Boreal Chorus Frogs generally increasing in abundance from coastal to transition strata. The probability of detecting anurans was equivalent in the BRSM and ISM strata, but much lower in the TRAN stratum. Wind speed likely influences detection probability (personal observation) and has been shown to influence calling in some anuran species (Oseen and Wassersug 2002). In 2005, average measured wind speeds (km per hour) were substantially higher on transects in the ISM (12.23 km per hr) and TRAN (11.08 km per hr) strata than in the BRSM strata $(5.78 \mathrm{~km}$ per $\mathrm{hr})$ and may have contributed to some of the observed variation in the probability of detection along this same gradient. We were unable to statistically test for an influence of weather variables because we surveyed relatively few $(n=26)$ transects, and because we were constrained to surveying multiple transects on the same day. However, we minimized weather influences on our ability to compare anuran abundance across strata and years by conducting surveys within NAAMP guidelines, although how well these guidelines apply in subarctic landscapes is not known. Moderate winds are generally present on our study area, and both Boreal Chorus Frogs and Wood Frogs call when winds exceed Beaufort 4 (personal observation), suggesting that we conducted surveys under conditions when anurans were likely to call.

The high intensity of calling anurans in the TRAN stratum, especially near transects $(<50 \mathrm{~m})$, may have limited the probability of detection of anurans farther away, resulting in a low overall probability of detection. Based on DISTANCE analyses, the TRAN stratum had a significantly smaller effective strip width $(22 \mathrm{~m})$ than either the ISM (76 m) or BRSM $(80 \mathrm{~m})$ strata. In contrast, density of anurans (species combined) increased substantially from the BRSM stratum
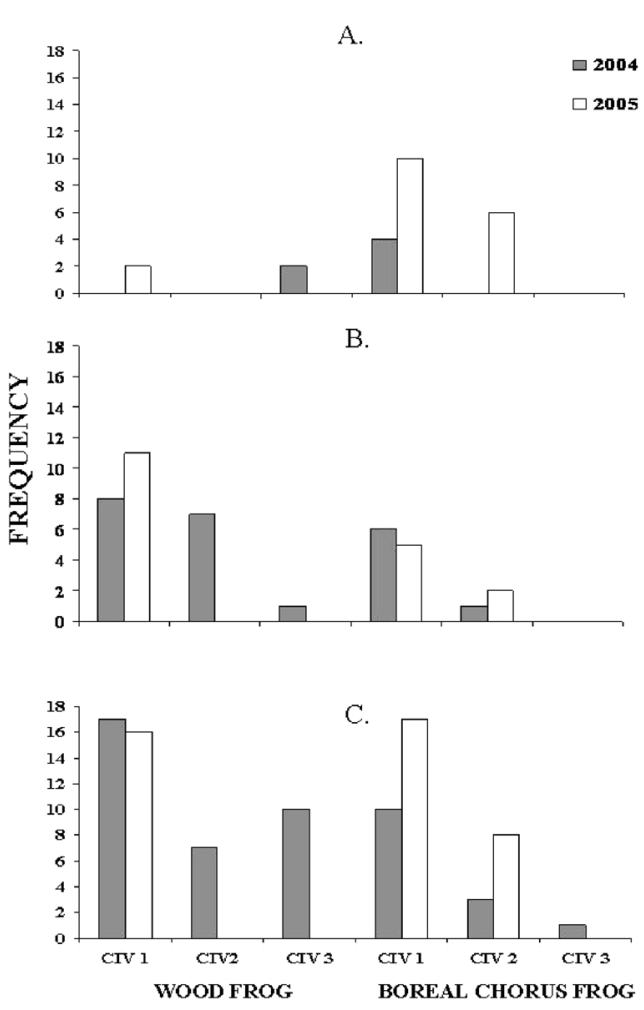

FigURE 2. Frequency of each level (1, 2, and 3) of call index values (CIV) observed for each anuran species (Wood Frog or Boreal Chorus Frog) in each year (2004 or 2005) in the (A) beach ridge-sedge meadow (BRSM), (B) interior sedge meadow (ISM) and (C) boreal forest-tundra interface (TRAN) in Wapusk National Park, Manitoba.

to the TRAN stratum. We similarly encountered Wood Frogs with higher frequency along the same gradient from BRSM to TRAN strata. However, we encountered Boreal Chorus Frogs more frequently in the BRSM stratum than in the ISM stratum, but most frequently in the TRAN stratum.

The magnitude of variation in encounter rates across strata was less than variation of density estimates derived using DISTANCE, and was most likely due to incorporating the cluster size of detections (i.e., how many animals are present) in DISTANCE. We used the CIV score of each detection as a relative measure of the minimum number of anurans present. These minimum density estimates were likely more appropriate than the relative measure of anuran abundance derived from encounter rates, which do not account for either the number of anurans present at each detection location or the probability of detection being $<1$.

Estimated density and encounter rates were highest in the TRAN stratum. Weather conditions in the BRSM 
and ISM strata are strongly influenced by Hudson Bay, which can remain frozen for up to 9 months of the year. Even though both Wood Frogs and Boreal Chorus Frogs are able to survive through harsh winter conditions using cryoprotectants, they may experience greater survival and reproductive success in the comparatively milder conditions that exist near the boreal forest edge (Herreid and Kinney 1967). Conditions conducive to breeding may arrive earlier in the spring farther from Hudson Bay resulting in spatial variability in calling anurans. More complex vegetative structure near the boreal forest may also provide more and better hibernacula and cover from predators for both adults and larvae. Coastal areas are also where there is currently the greatest overlap between waterfowl, wetland impacts from waterfowl herbivory, and anurans, and where we observed the lowest anuran densities. However, recent studies suggest the distribution of habitat use by geese is changing in this region (e.g., Nack and Andersen 2006) with geese increasingly using inland meadows for feeding. This may increase the extent of overlap between waterfowl and anurans, which may influence the future distribution and abundance of anurans in this region.

Although we pooled data across years, species, and strata, our sample sizes (i.e., the number of detections) were relatively small for distance analyses, primarily due to logistical and fiscal constraints of surveying an area accessible only by foot or helicopter during spring and summer. Furthermore, the utility of distance sampling is limited when species are rare and detections are few (Buckland et al. 2001). In the ISM and BRSM strata, we detected both Wood Frogs and Boreal Chorus Frogs infrequently, and thus estimates of detection probability and density were imprecise. We also were unable to use DISTANCE to estimate the probability of detection or density for each species within each of the three landscape types due to the low number of detections in the BRSM and ISM strata. Future surveys could incorporate increased sampling effort in some landscape types to obtain enough detections to precisely estimate density. In addition, our data suggested that anuran behavior may be influenced by observers. Anuran detection frequency within $10 \mathrm{~m}$ of transects was lower than detection frequency farther from transects. In our analyses, we accounted for an observer effect by removing detections $<10 \mathrm{~m}$ from transects and assuming the probability of detection was one at $10 \mathrm{~m}$. However, this truncation reduced sample size. Alternative methods that would reduce possible observer effects on detections should be considered for future anuran surveys in this region.

Ours is one of the first studies to examine detection and patterns of distribution and density of anurans at a landscape scale in a subarctic tundra ecosystem. Because arctic and subarctic regions are projected to experience dramatic changes in climate, and because biotic factors (e.g., intensive and extensive foraging by waterfowl) have already affected arctic and subarctic landscapes, it is imperative to better understand current anuran distribution and abundance. Our data provide a critical first assessment of the distribution and ecology of subarctic-dwelling anurans in the Hudson Bay Lowlands and highlight some of the factors necessary to consider when developing programs to monitor anurans in arctic and subarctic regions.

\section{Acknowledgments}

We thank Parks Canada, Wapusk National Park for providing funding for helicopter support to conduct anuran calling surveys in 2004 and 2005. Manitoba Conservation, the Mississippi Flyway Council, and Parks Canada provided logistical support in the form of maintenance and operation of the Nestor One research camp at Cape Churchill, from which we conducted surveys. Hudson Bay Helicopters, Ltd. provided flight support. We especially wish to acknowledge B. Reichert, M. Gillespie (Manitoba Conservation), B. Reside (Parks Canada), and J. Brauner, S. Dewindt, and R. Doty of Hudson Bay Helicopters for their efforts in support of field work in 2004 and 2005. We acknowledge D. LaPointe (U. S. Geological Survey), G. Perry (Texas Tech University), and K. Stewart (University of Manitoba) for comments improving this manuscript.

\section{Literature Cited}

Abraham, K. F., and R. L. Jefferies. 1997. High goose populations: causes, impacts, and implications. Pages 2-72 in Arctic ecosystems in peril: report of the arctic goose habitat working group. Edited by B. D .J. Batt. Arctic Goose Joint Venture special publication, U.S. Fish and Wildlife Service, Washington, D.C., and Canadian Wildlife Service, Ottawa, Ontario.

Alford, R. A., and S. J. Richards. 1999. Global amphibian declines: a problem in applied ecology. Annual Review of Ecology and Systematics 30: 133-165.

Ankney, C. D. 1996. An embarrassment of riches: too many geese. Journal of Wildlife Management 60: 217-223.

Bishop, C. A. 1992. The effects of pesticides on amphibians and the implications for determining causes of declines in amphibian populations. Pages 67-70 in Declines in Canadian amphibian populations: designing a national monitoring strategy. Occasional paper (76). Edited by C. A. Bishop and K. E. Petit. Canadian Wildlife Service, Ottawa, Ontario.

Bishop, C. A., and K. E. Petit. Editors. 1992. Declines in Canadian amphibian populations: designing a national monitoring strategy. Occasional paper (76). Canadian Wildlife Service. Ottawa, Ontario.

Brook, R. K. 2001. Structure and dynamics of the vegetation of Wapusk National Park and the Cape Churchill Wildlife Management Area of Manitoba: community and landscape scales. Thesis, Natural Resources Institute, University of Manitoba, Winnipeg, Manitoba.

Buckland, S. T., D. R. Anderson, K. P. Burnham, J. P. Laake, D. L. Borchers, and L. Thomas. 2001. Introduction to distance sampling. Oxford University Press, London. 
Burnham, K. P., and D. R. Anderson. 2002. Model selection and inference: a practical information-theoretic approach, Second Edition. Springer-Verlag, New York, New York.

Burrowes, P. A., R. L. Joglar, and D. E. Green. 2004. Potential causes for amphibian declines in Puerto Rico. Herpetologica 60: 141-154.

Bury, R. B., P. S. Corn, C. K. Dodd, R. W. Diarmid, and N. J. Scott. 1995. Amphibians. Pages 124-127 in Our living resources: a report to the nation on the distribution, abundance, and health of U.S. plants, animals, and ecosystems. Edited by E. T. LaRoe, G. S. Farris, C. E. Puckett, P. D. Doran, and M. J. Mac. U.S. Department of the Interior, National Biological Service, Washington, D. C.

Corn, P. S., and E. Muths. 2002. Variable breeding phenology affects the exposure of amphibian embryos to ultraviolet radiation. Ecology 83: 2958-2963.

Crump, D., M. Berrill, D. Coulson, D. Lean, L. McGillivray, and A. Smith. 1999. Sensitivity of amphibian embryos, tadpoles, and larvae to enhanced UV-B radiation in natural pond conditions. Canadian Journal of Zoology 77: 1956-1966.

Didiuk, A. B., and D. H. Rusch. 1979. Ecology of broods of Canada Geese in northern Manitoba. Final research report, Wisconsin Cooperative Wildlife Research Unit, Madison, Wisconsin.

Herreid, C. F., and S. Kinney. 1967. Temperature and development of the Wood Frog, Rana sylvatica, in Alaska. Ecology 48: 579-589.

Herman, T. B., and F. W. Scott. 1992. Assessing the vulnerability of amphibians to climatic warming. Pages 46-49 in Declines in Canadian amphibian populations: designing a national monitoring strategy. Occasional paper (76), Edited by C. A. Bishop and K. E. Petit. Canadian Wildlife Service, Ottawa, Ontario.

Heyer, W. R., M. A. Donnelly, R. W. McDiarmid, L. C. Hayek, and M. S. Foster. Editors. 1994. Measuring and monitoring biological diversity: standard methods for amphibians. Smithsonian Institution Press, Washington, D. C.

Jano, A. P., R. L. Jefferies, and R. F. Rockwell. 1998. The detection of vegetational change by multitemporal analysis of LANDSAT data: the effects of goose foraging. Journal of Ecology 86: 93-99.

Jefferies, R. L. 2000. Allocthonous inputs: integrating population changes and food web dynamics. Trends in Ecology and Evolution 15: 19-22.

Johnson, B. 1992. Habitat loss and declining amphibian populations. Pages 71-77 in Declines in Canadian amphibian populations: designing a national monitoring strategy. Occasional paper (76), Edited by C. A. Bishop and K. E. Petit. Canadian Wildlife Service, Ottawa, Ontario.

Kerbes, R. H., P. M. Kotanen, and R. L. Jefferies. 1990. Destruction of wetland habitats by Lesser Snow Geese: a keystone species on the west coast of Hudson Bay. Journal of Applied Ecology 27: 242-258.

Kickert, R. N., G. Tonella, A. Simonov, and S. V. Krupa. 1999. Predictive modeling of effects under global change. Environmental Pollution 100: 87-132.

Lips, K. R., P. A. Burrowes, J. R. Mendelson III, and G. Parra Olea. 2005. Amphibian declines in Latin America: widespread declines, extinctions, and impacts. Biotropica 37: 163-165.

Madronich, S. 1993. UV radiation in the natural and perturbed atmosphere. Pages 17-61 in UV-B radiation and ozone depletion: effects on humans, animals, plants, microorganisms, and materials. Edited by M. Tenini. Lewis Publishers, Boca Raton, Florida.

Mannan, R. N. 2008. An assessment of survey methodology, calling activity, and habitat associations of Wood Frogs (Rana sylvatica) and Boreal Chorus Frogs (Pseudacris maculata) in a tundra biome. Thesis, Wildlife Science, Texas Tech University, Lubbock, Texas.

Nack, R. R., and D. E. Andersen. 2006. Brood movement of Eastern Prairie Population Canada Geese: potential influence of light goose abundance. Journal of Wildlife Management 70: 435-442.

Oseen, K. L., and R. J. Wassersug. 2002. Environmental factors influencing calling in sympatric anurans. Oecologia 133: 616-625.

Ovaska, K. 1997. The vulnerability of amphibians in Canada to global warning and increased solar ultraviolet radiation. Pages 206-225 in Amphibians in decline: Canadian studies of a global problem. Edited by D. M. Green. Conservation Monograph (1), Society for the Study of Amphibians and Reptiles, St. Louis, Missouri.

Pounds, J. A. 2001. Climate and amphibian declines. Nature 410: 639-640.

Shelford, V. E., and A. C. Twomey. 1941. Tundra animal communities in the vicinity of Churchill, Manitoba. Ecology 22: 47-69.

Stuart, S. N., J. S. Chanson, N. A. Cox, B. E. Young, A. S. L. Rodrigues, D. L. Fischman, and R. W. Waller. 2004. Status and trends of amphibian declines and extinctions worldwide. Science 306: 1783-1786.

Thomas, L., J. L. Laake, S. Strindberg, F. F. C. Marques, S. T. Buckland, D. L. Borchers, D. R. Anderson, K. P. Burnham, S. L. Hedley, J. H. Pollard, J. R. B. Bishop, and T. A. Marques. 2005. DISTANCE 5.0, Beta 5. Research Unit for Wildlife Population Assessment, University of St. Andrews, St. Andrews (Scotland) U.K.

Walter, S. E. 1999. Nesting ecology of Eastern Prairie Population Canada Geese. Dissertation, University of Wisconsin, Madison, Wisconsin.

Weir, L. A., and M. J. Mossman. 2004. The protocol and history of the amphibian calling survey of the North American Amphibian Monitoring Program (NAAMP). Pages 565584 in Status and conservation of US amphibians, volume 1. Edited by M. J. Lannoo. University of California Press, Berkeley, California.

Wellein, E. G., and H. G. Lumsden. 1964. Northern forests and tundra. Pages 67-76 in Waterfowl tomorrow. Edited by J. P. Lunduska. United States Government Printing Office, Washington, D.C.

Wells, K. D. 1977. The social behaviour of anuran amphibians. Animal Behavior 25: 666-693.

Wrigley, R. E. 1974. Ecological notes on animals of the Churchill region of Hudson Bay. Arctic 27: 201-213.

Received 24 October 2007

Accepted 18 February 2009 